\title{
Modeling and Accomplishment of Loading-and- Unloading Equipment Optimum Allocation System at Bulk Terminal
}

\author{
Xueping Wang \\ School of Logistics Engineering, Wuhan University of Technology, Wuhan, China \\ Email: 419212827@qq.com \\ Lei $\mathrm{Wu}$ \\ School of Logistics Engineering, Wuhan University of Technology, Wuhan, China \\ Email: wulei8628@163.com \\ Mingwang Dong \\ School of Logistics Engineering, Wuhan University of Technology, Wuhan, China \\ Email: dongmingwang2002@163.com
}

\begin{abstract}
The configuration of port's loading-andunloading equipment is an optimization problem, which endeavors to put limited handling equipment to each operating line to achieve the maximum overall production efficiency. We set up the T-stage decision-making model of loading-and-unloading line equipment configuration by using the method of Multi-stage Decision, and design the algorithm of the mathematical model. Research results in this paper lay the foundation for the development of loading-and-unloading equipment configuration system, and provide scientific basis for the decision of type selection and rational quantity of loading-and-unloading equipment.
\end{abstract}

Index Terms - configuration, Multi-stage decision, loadingand-unloading equipment, dynamic programming

\section{INTRODUCTION}

With the transformation of the ports management system, ports take an increasing essential role in promoting China's development, and the production management at ports is especially important. Production Scheduling is one of the most important parts in port production management, what's more, loading-andunloading equipment configuration is the key task, which is directly related to whether the port can make effective use of its resources and potential. Therefore, researches on the port production scheduling model and advanced scheduling algorithm have become a hotspot.

At the present stage, China's port enterprises are still in the stage of experience management when organizing production, configuration loading-and-unloading equipment and choosing loading-and-unloading process program, relying on the experts who have being engaged in scheduling production and conducting loading-and-

Manuscript received February 16, 2011; revised March 28, 2011; accepted April 3, 2011. unloading process long, and it would have a large haphazardly and a certain lack of basis for making scientific decision. Thus, how to achieve a scientific and rational configuration of the production resources has become an urgent issue.

With this background, fuzzy dynamic programming algorithm is applied to build the model of the bulk commodity loading-and-unloading equipment configuration optimization system and seek the solution ${ }^{[1-5]}$. The advanced technology of Web Services is applied in the production scheduling at bulk terminal.

\section{PRODUCTION MANAGEMENT ANALYSIS OF BULK TERMINAL}

Generally speaking, bulk commodity refers to cargo with package and without package, according to the packaging form which can be classified into several categories: bags, bales, barrels and cylinders, cartons, baskets, altars and non-packed. For the variety of the cargo, management at bulk terminal is definitely complicated.

The operation type of storage yard at bulk terminal is assorted into three sorts: export, import, and other operations (excluding export and import). Respectively, export operation consists stocking from vehicles to yard, ship loading from yard to ships, directly loading from vehicles to ships, and shutting out from yard to vehicles. Import operation includes unloading from ships to yard, carrying from yard to vehicles, and directly carrying from ships to vehicles. Other operations (excluding export and import) comprise replacing stock from yard to yard, filling package, scattering package and ship changing.

The production management at bulk terminal focuses on recording the actual loading-and-unloading operation of the production process accurately, which is in the charge of the first-line tally clerk and custodian. For shipping operations, the tally clerk is responsible for 
recording the site changes when loading and unloading ships; however, for land operating, it is the custodian who records the site changes when loading and unloading vehicles. The recording media is shift bills, which is back to the storehouse checker to check the loading-andunloading conditions of the whole ship, and count the yard inventory, the terminal throughput, and other important information after the operation is completed. The appearance of the shift bills means the inventory changes, which can track the inventory and can be the basis of the storehouse inquiry. The accuracy of the data directly affects the extent of difficulties to schedule the yard plan and the loading-and-unloading production deployment, so the management of the shift bills is the most important thing in production management. In addition, the track of the dynamic information during dispatch is also important, such as the operation of the transport machine on the yard, the arrival-and-departure of the ship and the progress of loading-and-unloading, which plays a crucial role in production dispatch.

Furthermore, there are a lot of factors affecting the efficiency along the loading-and-unloading production line. For example, ship type, cargo type and package, the number of the loading-and-unloading equipment, process program, implements and appurtenances, and operation environment.

\section{OPTIMIZATION ALLOCATION MODEL OF THE LOADING- AND-UNLOADING EQUIPMENT}

The decision problem of the loading-and-unloading equipment configuration refers to the schedule of the port resources, which is one of the important problems in port schedule, and has a tremendous influence on decreasing the logistics cost and increasing the logistics efficiency. That is to say that how to schedule the port resources suitably to complete the loading-and-unloading tasks of the arriving ships by minimum cost and maximum efficiency.

During the production scheduling process at bulk terminal, the plan dispatchers usually face this situation: several tasks share the same specific resource, meanwhile the limited resources can't meet all the tasks' needs at the optimal condition relative to each individual task. The main reason of such production scheduling problem is that production resources are restricted ${ }^{[6]}$.

\section{A. Model Establishment}

Firstly, assuming the number of the operating unit $\mathrm{T}$ is given, the aim of the model is to choose $\mathrm{T}$ control parameter values $u_{0}, u_{1}, \cdots, u_{T-1}$, make the state variables start from $x_{0}$, through $x_{1}, x_{2}, \cdots, x_{T-1}$, finally, guarantee $x_{T-1}$ to achieve the expected effect (maximum operating efficiency). This process can be defined as decision-making of stage $T$. Now on the assumption that in stage $t$ (unit $t$ operating line), the value of $u_{t}$ is limited to the fuzzy set
$C^{t}=F(U), t=0,1, \cdots, T-1$. Termination $\quad x_{T-1}$ is decided by $x_{T-2}$ and $u_{T-2}$, and $x_{T-2}$ is decided by $x_{T-3}$ and $u_{T-3}$, date back to its sources, $x_{T-1}$ is determined by $u_{0}, u_{1}, \cdots, u_{T-1}$ and $x_{0}$.

Explanation of relevant variables and parameters:

$T$ - the number of operating units to be solved

$K_{t}$ - the total amount of operations in unit time of certain loading-and-unloading equipment assigned by unit $t$

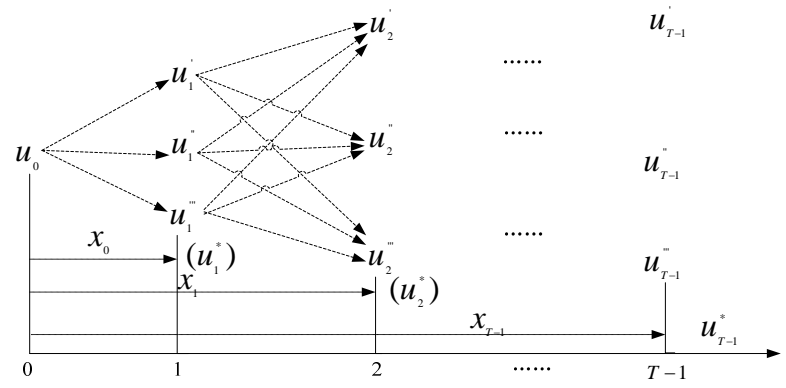

Figure 1. Decision-making of stage $\mathrm{T}$

$G_{t}$ - the total amount of operations in unit time of the portal crane assigned by unit $t$

$t$-operating unit to be configured

$E_{t}$ - Relative operating efficiency

$u_{t}$ - the number of certain type of equipment assigned by unit $t$

$e_{t}$ - the amount of operations in unit time of some type of loading-and-unloading equipment in unit $t$

$K_{m t}$ - the amount of operations in unit time of No. $m$ portal crane in unit $t$

$Q_{t}$ - The quantity of portal crane assigned by unit $t$

$L$ - The total number of some type of the schedulable loading-and-unloading equipment;

$T_{t}$ - The actual operation time of unit $t$

$T_{t}^{*}$ - The permit operation time of unit $t$

$Z_{t}$ - The total of the handling goods in unit $\mathrm{t}$

$C^{t}$ - The fuzzy set of the $u_{t}$ at stage $t$ (unit $t$ )

$\mu_{\lambda}(t)$ - The membership function of $C^{t}$ at stage $t$

$\tilde{C}^{t}$ - The triangular fuzzy number of fuzzy set $C^{t}$ at stage $t$

$\beta_{t}$-Optimization index, which is used to reflect the views of the decision makers.

Now take some type of loading-and-unloading machinery (such as crane, notes as $K$ ) for example, because the production capacity of the whole loading and 
unloading line has been limited by the operation ability of the portal crane $(G)$, now assuming that during article $t$, the operation efficiency of $K$ relative to $G$ is $E_{t}$, then the system objective function is :

$$
\begin{gathered}
Z_{\max }=\sum_{t=o}^{T-1} E_{t} \\
\text { s.t. } \quad 0<E_{t}<1
\end{gathered}
$$

In (1),

$$
\begin{aligned}
& E_{t}=K_{t} / G_{t}=u_{t} \cdot e_{t} / \sum_{m=1}^{Q_{t}} K_{m t} \\
& \text { s.t. }\left\{\begin{array}{l}
E_{t}= \begin{cases}1 & K_{t} \geq G_{t} \\
(0,1) & K_{t}<G_{t}\end{cases} \\
t=1,2, \cdots, T-1
\end{array}\right\} \begin{array}{l}
\sum_{t=0}^{T-1} u_{t}=L \\
m=1,2, \cdots Q_{t}
\end{array}
\end{aligned}
$$

Put (2) in (1), then

$$
Z_{\max }=\sum_{t=0}^{T-1} u_{t} \cdot e_{t} / \sum_{m=1}^{Q_{t}} K_{m t}
$$

Extracting the fuzzy constant in (3), supposing

$$
C^{t}=e_{t} / \sum_{m=1}^{Q_{t}} K_{m t}
$$

So the objective function of the system after optimizing becomes into:

$$
Z_{\max }=\sum_{t=0}^{T-1} u_{t} \cdot C^{t}
$$

Considering that there is the key operation unit practice, which means that the operating time of the key operation unit can't exceed the permitted time. So

$$
T_{t} \leq T_{t}^{*}
$$

In practical operation, not all the working ships are key ships. So not each operating unit has its relative $T_{t}$ and $T_{t}^{*}$. Only key operating unit has these two parameters, and in other operating units, it can be considered that $T_{t}$ is less than $T_{t}^{*}$ constantly.

$$
T_{t}=Z_{t} / \min \left(K_{t}, G_{t}\right)
$$

Therefore the constraints of objective function in (4) is

$$
\text { s.t. }\left\{\begin{array}{l}
0<C^{t}<1 \\
\sum_{t=0}^{T-1} u_{t}=L \\
u_{t}>0, u_{t} \text { is integer } \\
Z_{t} / \min \left(u_{t} \cdot e_{t}, \sum_{m=1}^{Q_{t}} K_{m t}\right) \leq T_{t}^{*} \quad t=0,1,2, \cdots, T-1
\end{array}\right.
$$

\section{B. The solution to the mathematics model for the} loading-and-unloading equipment configuration

The design of the solution algorithm is shown in Fig. 2. The main variables and parameters can be explained as follow.

$$
\begin{aligned}
& k \text { - the current operating unit to be configured } \\
& t \text { - the number of the current process' recursion } \\
& T \text { - the number of operating unit }
\end{aligned}
$$$$
\operatorname{arr}[] \text { - One-dimensional array which to store the }
$$
relative efficiency of each operating unit

$$
i, j, m, E \text { - Alternative variable; }
$$

array[] — One-dimensional array which to store all values in calculation at stage $T$

$d[]$ - One-dimensional array which to store the optimal value of every stage in calculation at stage $T$

$$
\begin{aligned}
& e[] \text { - Alternative array } \\
& Z_{\max } \text { - the maximum efficiency in calculation }
\end{aligned}
$$

The program flow can be described as shown in Fig. 3. Calculation of an example:

Decision-making method of stage $T$ is used in this model example, which can be explained by taking a certain type of loading-and-unloading equipment (as K) of bulk terminal for example.

Assumption of the initial value

Let us suppose that the number of the operating unit of bulk terminal at some time is : $T=4$, the quantity of a certain type of loading-and-unloading equipment can be scheduled as : $L=10$, the value of $\widetilde{C}^{t}$ can be received from the calculation of statistical database $\left(c_{1}^{t}\right.$ is the minimum in the historical statistical database, $c_{3}^{t}$ is the maximum in the historical statistical database, and $c_{2}^{t}$ is the value which appears the most times in the historical statistical datebase), as the table below:

TABle I. The VAlue of TRIangular Fuzzy Number $\stackrel{\sim}{C}^{t}$

\begin{tabular}{|c|c|c|c|}
\hline$t$ & $C_{1}^{t}$ & $C_{2}^{t}$ & $C_{3}^{t}$ \\
\hline 0 & 0.20 & 0.24 & 0.26 \\
\hline 1 & 0.22 & 0.25 & 0.28 \\
\hline 2 & 0.24 & 0.26 & 0.28 \\
\hline 3 & 0.21 & 0.25 & 0.27 \\
\hline
\end{tabular}

So the initial value is:

TABLE II. THE INITIAL VALUE OF THE MODEL

\begin{tabular}{|c|c|c|c|c|c|}
\hline$T$ & $L$ & $C^{0}$ & $C^{1}$ & $C^{2}$ & $C^{3}$ \\
\hline 4 & 10 & 0.235 & 0.253 & 0.258 & 0.245 \\
\hline
\end{tabular}




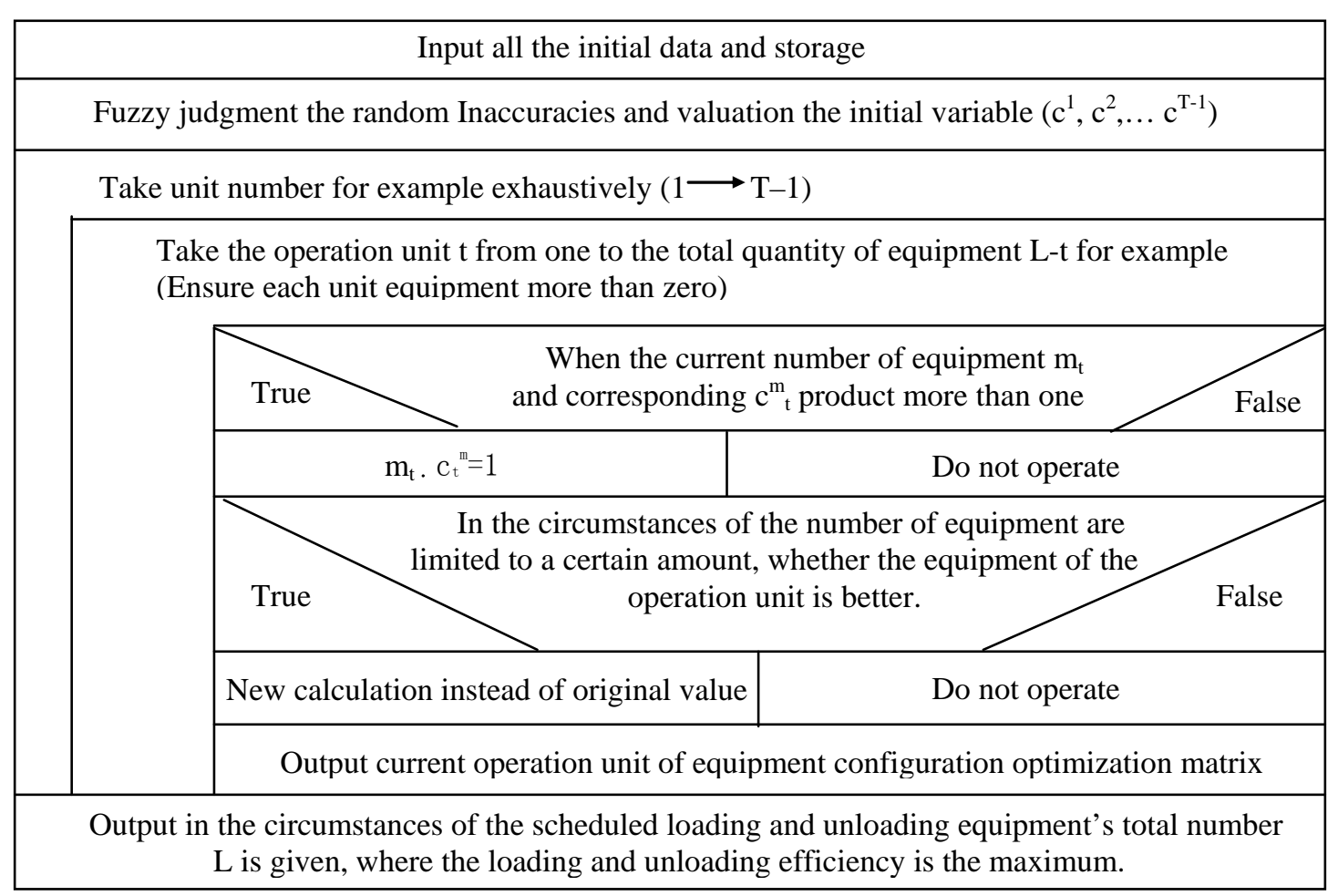

Figure 2. The dynamic programming realization N-S figure of loading-and-unloading equipment configuration optimization problem

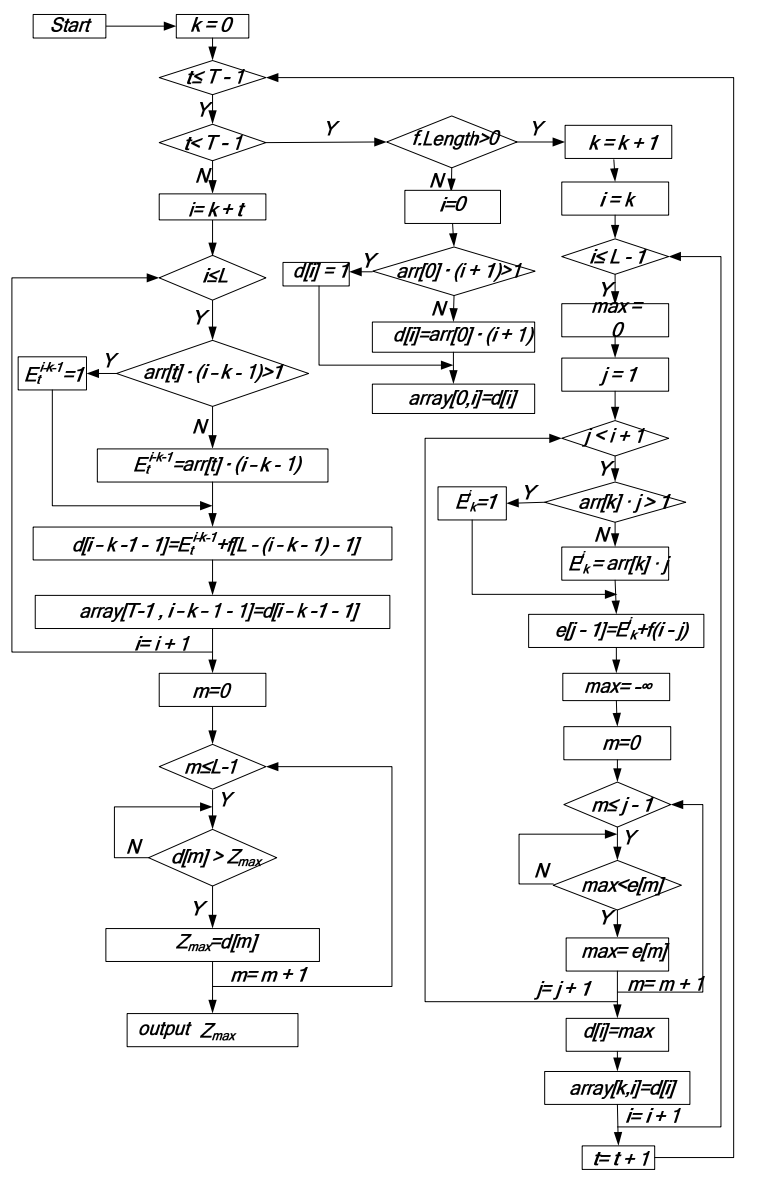

Figure 3. The dynamic programming realization process flowchart of the loading-and-unloading equipment configuration optimizating
In addition, assuming stage $t=3$ as the key operating unit, loading-and-unloading operations should be completed within 24 hours. When only portal crane is considered, all work can be completed within 16 hours. This important operating problem can be denoted as follows:

$$
Z_{3} /\left(G_{3} \cdot u_{3} \cdot C^{3}\right) \leq 24, Z_{3} / G_{3}=18, C^{3}=0.245
$$

So the key operating unit should satisfy: $u_{3} \geq 3, u_{3}$ is integer.

The solution to the model using decision-making in stage $T$

Calculated in accordance with the above method, the best path to achieve is shown in Fig. 4 .

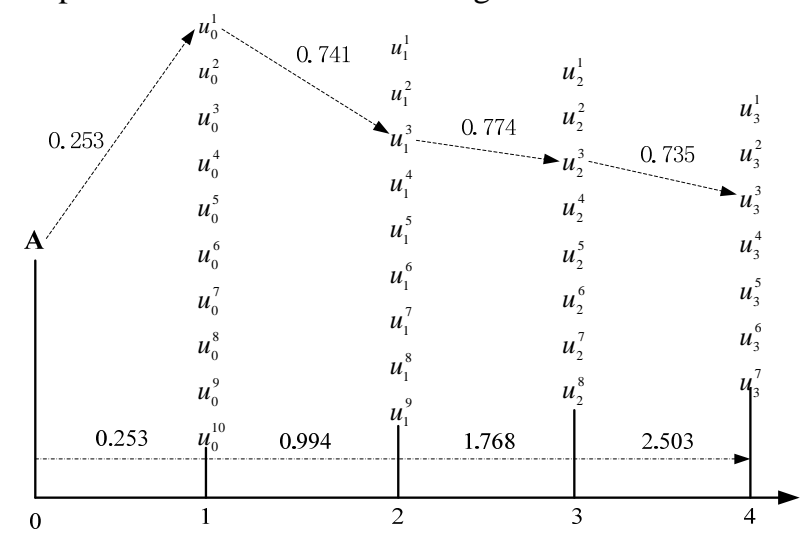

Figure 4. The best path of decision-making of stage $T$ 
In the assumptive plan, stage $t=3$ is the key operating unit, and the constraint is $u_{3} \geq 3$, so when the solution to the model, $Z_{\max }$, equals to the maximum, the value of $u_{3}$ can satisfy the requirements of the key operating unit, that is to say, this program is the best. If the most efficient configuration program cannot meet the time requirements of the key unit, then suboptimal solution can be selected for checking by analogy until the distribution plan can meet the requirements of the key operating unit.

In the actual production process, when the operating conditions change, for example if an operating unit is completed, or there is another ship arrived port, this mathematical model can be used to reconfigure. The operating cargo amount of each unit needed to be operated change corresponding according to the new situations. Through using this model repeatedly, the dynamic allocation of port equipment can be realized, which lead to maximize operating efficiency.

Conclusion about this part: As shown in Figure 4, the best path of decision-making of stage $\mathrm{T}$, because of the fuzzy number corresponding to the first operating unit is the minimum (0.245), the number of equipment assigned to this unit is the fewest, and so on. It shows that this mathematical model reflects the efficiency priority strategy in the process of the actual portal dispatch well. Meanwhile, the result of this dispatch illustrates: on the premise of showing the priority strategy of key operating unit, the dispatch of the general portal operating is still mainly based on the condition of the existing machinery and equipment to meet the requirements of the higher level and in order to achieve the main target--the maximum efficiency of the overall operation.

As to the above tables, we can summary that under the constraints of the objective function in this mathematical model, with the increasing of the number of machinery and equipment $\mathrm{L}$, the range of the optimal dispatching value tends to be stable. That's to say, if the optimal dispatching value has no change during this period, the operation of this algorithm has better convergence effect.

According to the above analysis, it can be concluded that: the mathematical model of the configuration optimization of loading-and-unloading equipment at bulk terminal established in the paper could better reflect the actual dispatching situation. When several ships arrive in the interval, the key ship should be scheduled preferentially due to the priority strategy; and when the number of the equipment is limited, in order to achieve the target that the detention time of all ships should be able to as short as possible (to maximize the overall operating efficiency), the operating unit with the maximum relative efficiency will be scheduled preferentially. What's more, through the dynamic programming algorithm designed for this reference model, we can obtain the optimal value of the equipment configuration, and the optimal results can be used as the reference of the actual portal scheduling.

\section{IV.ANALYSIS AND DESIGN OF THE CONFIGURATION OPTIMIZATION SYSTEM}

At present, along with cargo transport becoming logistically, the information transmission tending to electronization, digitization, and the traditional transport notion has already changed from the pure goods transport into an unlimited extension and current economic chain, which includes logistics, information flow, and capital flow in one, throughout the whole process of produce goods to consumption. Ports are the most important node in a modern logistics system and are also the information distribution center of goods. Ports hold the irreplaceable superiority by its formalization's collection and distribution ability, most likely to become the hub of the entire system and value-added service center. Usisng information technology, Ports' enterprises can enhance their core competitiveness and optimize business operations resources, improve efficiency, a further decline in the cost of business operations, services more customer satisfaction, and ultimately make the ports, shipping companies and cargo owners, and other parties to win. This was mainly due to logistics information technology not only can be used for business transactions between enterprises, but could also cause internal operation and management and production process becomes scientific and efficient.

Because the configuration of loading-and-unloading equipment at port has the characteristics of non-structural, multi-stage, multi-objective decision-making, the configuration optimization system which has been designed in this article gives an overall analysis. Not only the production operating characteristics of bulk terminal has been full studied on, but also dividing the configuration process into several stages and displaying the calculation results of each stage. Decision-makers will interact with the computer to complete each stage decision, and then draw up a homologous arrangement plan, the decision-makers could selected the satisfaction plan for the implementation of execution.

\section{A. System analysis}

\section{(1) Analysis of import process}

Import business process is the production process for import voyages. As an import voyage, it begins from the scheduling department receiving the ship tasks from port authority to the whole goods being taken away. The transmission of information and relationship among staff and main functional department are shown in Fig. 5

(2) Analysis of export process

Export business process is the production process for export voyages. As an export voyage, it begins from the collection of goods, and then the scheduling department receiving the ship situation, finally all the goods of this voyage being loaded on board. As it shown in Fig. 6

(3) Analysis of functional requirements

The configuration optimization system which designed in this paper has such basic functions: operating line machine for port machinery, operating line efficiency calculation, operating line of mechanical configuration optimization, real time statistics for important resources, 


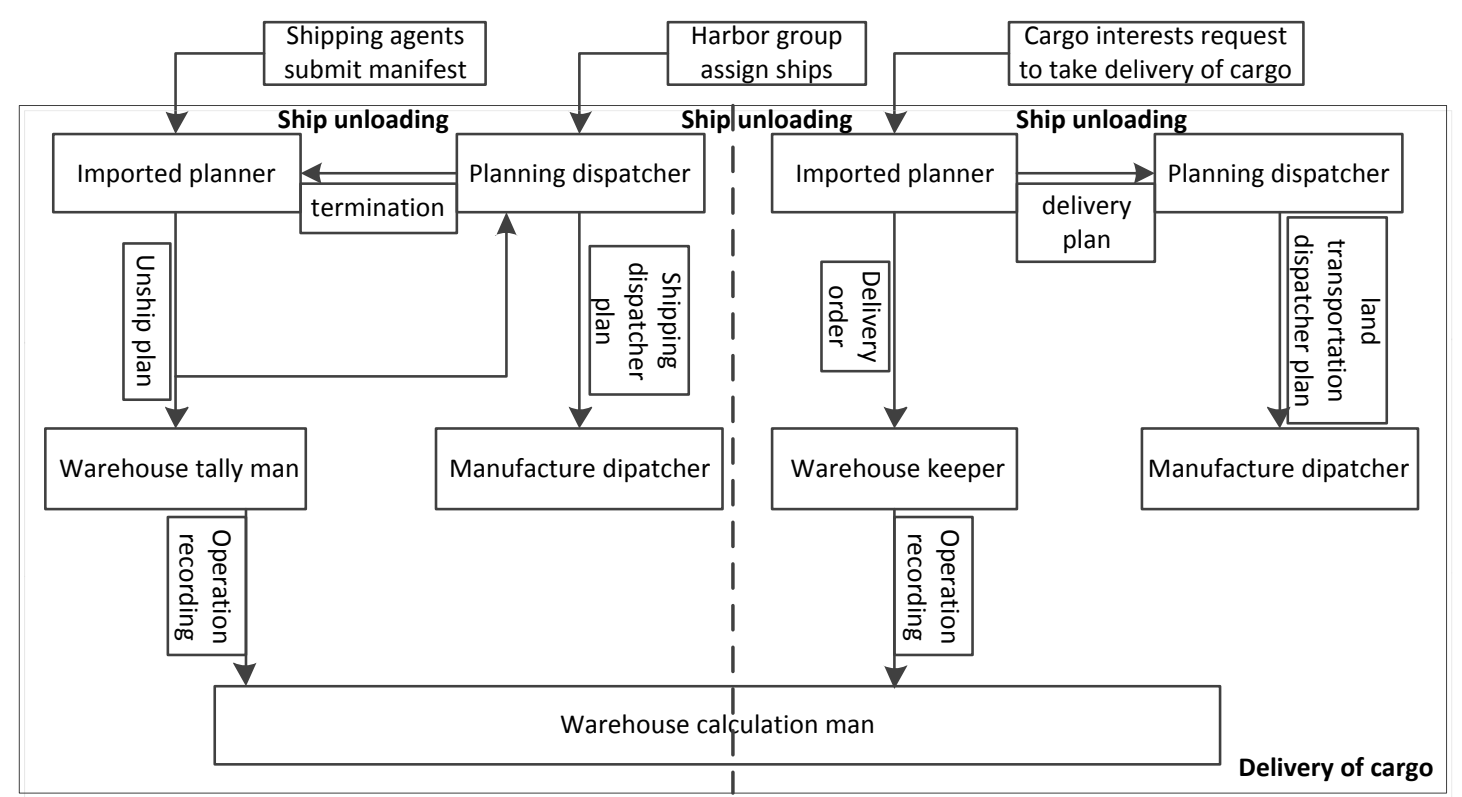

Figure 5. Imported business process

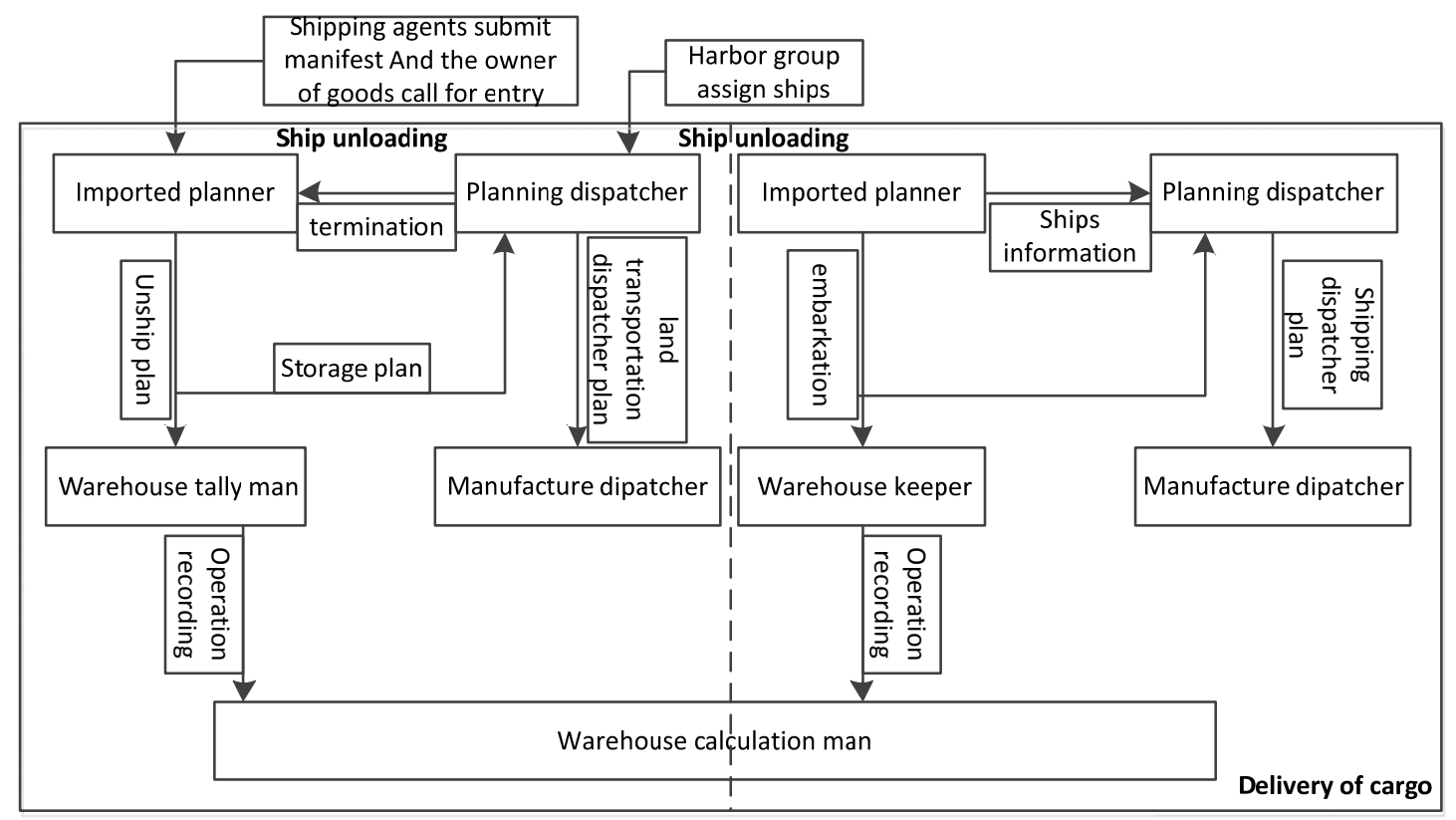

Figure 6. Export business process

data analysis and print out. In the process of using, the system will provide the right information for the users and it also can call the model calculations automatically. The aims of this system is give a method to solve the current port handling equipment configuration problems, make use of mechanical equipment and make the configuration is more rationalization .

The computer system is not simply to replace human decision making, but people-oriented, man-machine dialogue. The dispatcher (decision makers) will optimize handling equipment step by step base on work experience in computer-assisted. In the computer-aided decisionmaking system, the combination of qualitative and quantitative methods, decision-making programs will be highly targeted and motivated to meet the port operation needs.

\section{B. System design}

(1)Structure design for system.

The handling equipment optimizing system of general cargo terminal is consisted of equipment management background systems and Web Services-based optimization of decision support system. Equipment management background system runs a unified management for handling machinery of general cargo terminal, handling tools, handling technology etc. Decision support system provides the visual business interface, facilitates the interaction between decisionmakers and the database by calling the intelligence tools 


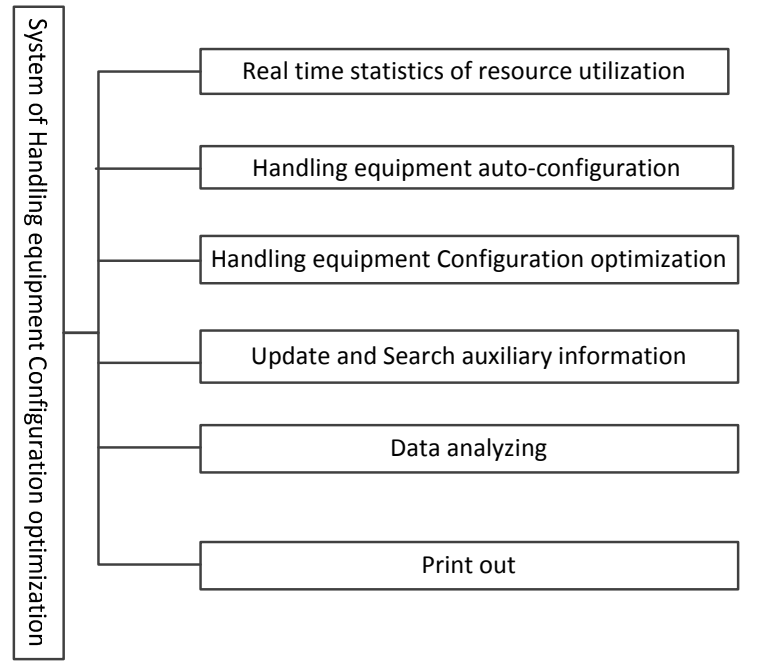

Figure 7. Functional module of the Configuration Optimization system

engine, and displays the results of decision analysis. Decision support system extracts data of equipment management background system from the database, through filtering and data conversion; finally it is loaded into the data set for data integration. In the data set, the data is stored in accordance with the decision subject to multi-dimensional approach, constitutes data sources for decision analysis tool. Data mining tools are mostly used for data classification and estimation, and then found the potential information according to the data mining model.
The results defined by decision support tools are often not intuitive and difficult to read. However, through a graphical user interface, decision analysis can be visually displayed to the decision makers; it is convenient for the interaction of users.

For the completion of various business functions, the architecture of system is based on B / S (Browser / Server) mode (Fig. 3), which is the client browse, web application server and database server mode. Users access applications through a browser, send application request; Web application server access the database after receiving the user's request, and returns the results to the client. This structure not only liberate client form the heavy burden and the requirements of improvement, but also freed the technical maintenance personnel from the heavy maintenance upgrade works. As the client impart the logic part of the transaction to the Web application server, reduce the load of client, it is not responsible for dealing with complex calculations, data access and other key matters anymore, so maintenance personnel can focus on the update of Web application server program. This three-tier structure, each layer is independent, changes of any layer will not affect the function of other layer, it fundamentally make up the defects of the traditional two-tier C / S (Client / Server) architecture, it is a profound change of application system architecture.

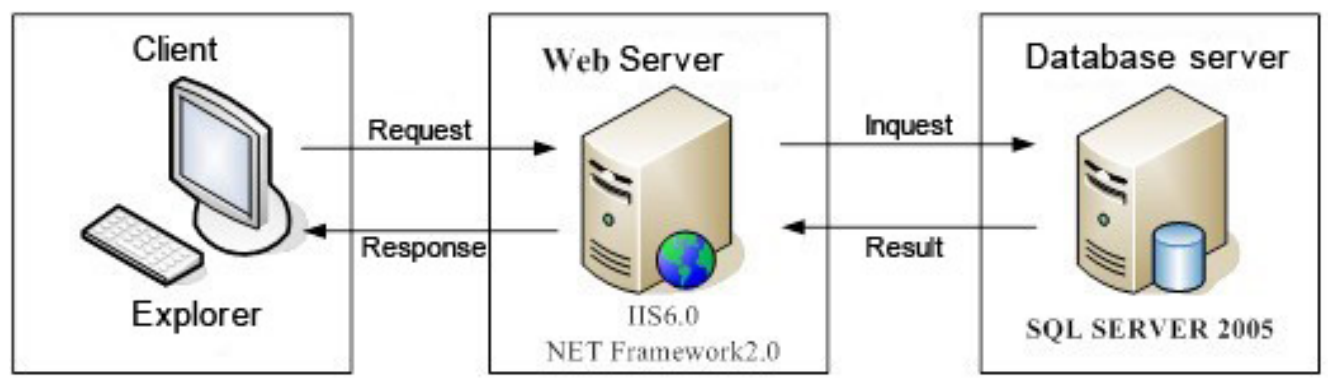

Figure 8. Three-tier structure of system

IIS6.0+.NET Framework2.0 is chosen to be Web application server, and IIS is the acronym for Internet Information Server, which is the main server of Microsoft and responsible for the response and forwarding requests from clients. .NET Framework is used to receive the forwarding requests, complete the data and logic treatment and return the results to clients. IE browser is chosen for clients, and MS SQL SERVER 2005 is chosen for its high stability, security and better compatibility with .NET Framework.

(2)Design for system process

Handling equipment configuration optimizing system should meet the two basic principles: First, match the efficiency, which is the operational efficiency of various types of machinery which are equipped in an operating line should be balance basically, the phenomenon of wait which is leaded by different operational efficiency; second, principle of priority to gantry crane. Because both the loading or unloading operations are inseparable from the gantry crane and the purchase price of the general cargo handling equipment in the company is the highest, because of irreplaceable, and its impact on the efficiency of berthing operations are the largest, so the satisfaction of the highest operating efficiency of gantry crane should be equipment configuration principle. The number of equipment configuration in the whole operation line is based on the maximum operating efficiency of gantry crane, in order to maximize the operating efficiency of the whole operation line. To make the number of configurations as reasonable as possible in the premise of meeting the maximum operating efficiency, reduce the waste of resources and costs which are caused by the mismatch of equipment.

Program flow of system mainly consists of the following steps:

First: Calculate the maximum operating efficiency of crane 
Second: Select the process of loading-and-unloading, and determine other machinery and equipment to deploy

Third: determine the operating efficiency and number of the level transport machinery to match the crane

Fourth: determine the operating efficiency and number of the yard machinery

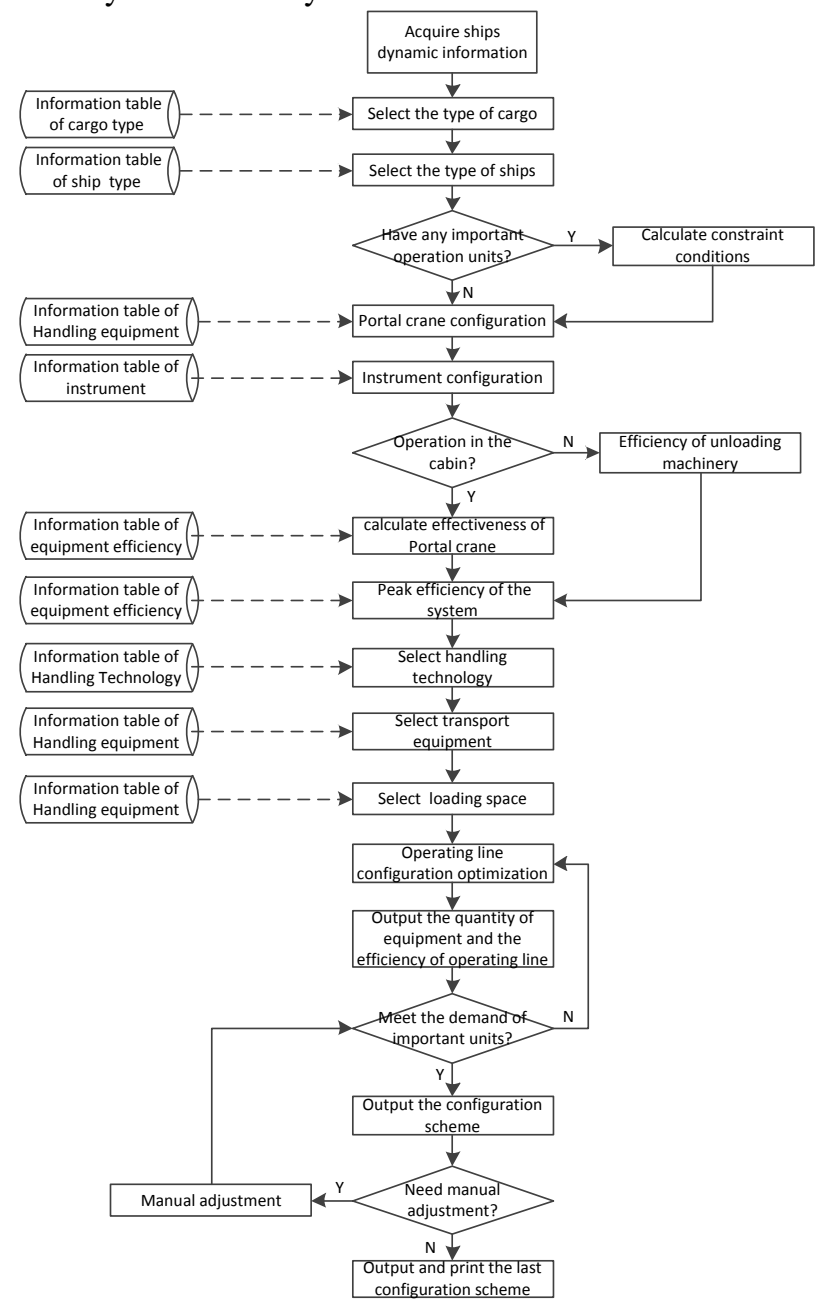

Programming flow of the Configuration Optimization system

In this chapter, the analysis method of structured information system is used to analyze the business processes and functional requirements of bulk terminal in detail, and make an overall design of system, which includes the design of structure, network topology, data flow and database. After making clear the development goal of system and the information requirements of client, logic program is put forward to provide the basis for the next phase to design of physical program.

\section{ACCOMPLISHMENT OF THE CONFIGURATION OPTIMIZATION SYSTEM}

The computing model of information system is composed of the logical and physical configuration of hardware, software and data resources and its way of working together. The development of computer and network technology promote the evolution of computing model of information system, makes it experience an evolutionary process from simple to complex, from primary to advanced. Most early information system used centralized computing model, such as stand-alone system and terminal-oriented multi-user system. With the development of computer and network technology, distributed computing model is becoming the main mode of information systems gradually, distributed computing model can be divided into three types such as shared resources, client / server (C / S) mode and browser / Web server ( B / S) mode. However, Internet technology, especially the rapid development and popularization of Web technology makes Web-based computing model of information systems become a new main trend, which use browser / Web server computing mode, therefore the exploitation and technology of Web-based information systems development has become a hot research.

The research and implementation of handling equipment optimizing system will be emphasis in the paper from the point of the Web Services-based technology system development technique. Implementation of the system regarded as later period stage of an information system development cycle, whose purpose is to transform the results of analysis and design of system to the system can actually operate. This chapter is based on the system design of preamble, applies ASP.NET technology to program development, implements handling equipment configuration optimizing of general cargo preliminarily.

The chapter constructs operation and development environment of the system according to the foregoing analysis and theory, and using Visual C \# language as the development language, combining SQL SERVER 2005 database, basing on ASP.NET and Web Services-based technology, build optimizing system platform of handling equipment configuration optimizing of general cargo, and achieve partial function. The application system research on the general cargo wharf of Tianjin Port, describes the implementation procedure of mechanical equipment configuration optimization in manufacturing operations of general cargo wharf.

\section{DISCUSSION AND CONCLUSION}

We set up the decision-making model of loading-andunloading line equipment configuration of stage by summarizing configuration optimization of cargo terminal handling equipment to Multi-stage decision, design the algorithm of the mathematical model, lay the foundation for the research and development of loadingand-unloading equipment configuration system, and provide scientific basis for the type selection and rational quantity of loading-and-unloading equipment.

There are also some problems or deficiency should be solved or discussed in the further research.

(1)General Cargo Terminal Production scheduling system is a very complex system, there are so many factors that affect the working efficiency, and these factors often exists interactional phenomenon. This article seizes the main aspects of the problem, conducts a number of assumptions and shields some intractable secondary factors when establishing handling equipment configuration optimization model. 
(2)The system has only a fuzzy evaluating indicator of handling efficiency. A practical optimization allocation system should introduce the other indicators such as economic evaluating indicator in order to comprehensive assessment, which need to be further improved.

(3)The features designed by system need to be further improved, we should get feedback information from the actual use of enterprise, thus the system's utility can be enhanced.

(4)Because of constrains of time and application conditions, some work of the system has not been completed, such as system coding maintenance, testing work of the system and so on.

\section{REFERENCES}

[1] Meng Yu, "The research of based on many Agent production scheduling system at container ports," Ph.D. Thesis, Wuhan: Wuhan University of Technology, 2007 (in chinese)

[2] Shean Bie and Gangsheng Wu, "Computer simulation method of engineering construction and operation process at ports," Port \& Waterway Engineering, Dec ,1997 pp.4953. (in chinese)

[3] Ming Du, "Optimizating software research on loading and unloading equipment configuration at port," Master Thesis, Wuhan: Wuhan University of Technology, 2003 (in chinese)

[4] Baojiang Zhu, "Determine the mathematical model of the flow machinery of reasonable ownership at port," Management of chinese equipment, Nov ,2000 (in chinese)

[5] Jietao Liu, "The key technology research of base on VR bulk terminal simulation platform," Master Thesis, Wuhan: Wuhan University ofTechnology, 2007 (in chinese)

[6] Zhenliang Jia and Zhigang $\mathrm{Si}$, "Based on tour vehicles scheduling design and simulation of hybrid integer programming,” Computer Simulation. Aug, 2007 pp.233235 (in chinese)

Xueping Wang was born in Jingmen, Hubei province in 1987,and received the Bachelor of Engineering degree in Wuhan University of Technology(WHUT) in 2009.She is Master of Engineering student at Wuhan University of Technology and majors in Logistics Technology and Equipment.

During her master study, she helped to complete the LNG applications of port machinery, Analysis of Simulation of Cargo Terminals Logistics System Based on Witness. Her research interests involve logistics system plan and simulation, loading and unloading technology on port, the model building for the system of logistics information.
Lei Wu was born in Lianyungang, Jiangsu province in 1986, and received the Bachelor of Management degree in Jingdezhen ceramic institute(JCI) in 2009. He is a fulltime Master of Engineering student in WHUT at present, his majors in port logistics management.

During his master study, he helped to complete The Logistics Park Design for Lengshuijiang and Xiangyin, Hunan province, Imported logs fumigated disinfestations for Tianjin port. His research interests involve logistics park design, the 3D model building and simulation for the system of logistics information, to solve the problems on traditional logistics with new technology.

Mingwang Dong was born in Yichang, Hubei province in 1963, and earned bachelor degree and master degree in Wuhan University of Water Transportation Engineering in China respectively in 1984 and 1987, and now he is a professor in Wuhan University of Technology(WHUT).Professor Dong is deputy president of School of Logistics engineering in WHUT and assistant secretary general of The China Mechanical Engineering Academic Society Port Machinery branch. He was awarded the leader of the Engineering center on Logistics Technology and Equipment in WHUT. And now Professor Dong is also deputy president of School of Logistics engineering in WHUT.

Professor Dong's majors in logistics system desgin and simulation, ports machinery CAD research and development, the logistics management on emergencies, strategies on area logistics, etc. He has published over 40 papers, presided over 30 research projects, acquired 8 patents. He was awarded third prize on Science and Technology Progress of Hubei province, second prize on Science and Technology Progress of Ministry of Communications, second prize on Association of Chinese Navigation.

His major writings includes: CAD analyses on mechanical design and Assembling(Computer \& Digital Engineering, 1995), The Structure Design of Expert System for Mechanical Design(Journal of Wuhan Transportation University,1996), The solution scheme of logistics information storage(Transportation Enterprise Management, 2002), The ratio of logistics cost in GDP(China Storage \& Transport, 2004), Design of Provider Administration System Based on Agent Technology(Journal of South China University of Technology(Natural Science), 2004), Thinking of China logistics (China Storage \& Transport, 2005), Simulation Model of Operation Process in Container Yard and Its Application in Design of Container Yard(Journal of Wuhan University of Technology(Transportation Science \& Engineering),2007), Advantage of backwardness on logistics industry (China Storage \& Transport, 2009), Research on Key Technologies of Establishing The Port Hoisting Equipment Object Library in Flexsim(IEEE CONFERENCES,2010). 